\title{
Design of Centralized PID Control System for Two Variable Processes based on Root Locus Technique
}

\author{
M.Swetha, R.Kiranmayi, N.Swathi
}

\begin{abstract}
This paper describes the design of centralized controller for two variable processes. The two variable process structures are somehow different from the single variable processes. This difference is occurred because of interrelations between the variables present in the process. Hence, when a controller is planned for such systems, the relations amid the variables must be taken into consideration. This process is done in decentralized control system design. But decentralized control system works well when the interrelations between the variables are simple. If the interaction is strong, then the centralized control system is preferred since it uses a controller for each pair of input and output variables. The controller used in main diagonal works for improving the servo performance and off diagonal controller reduces the interrelation effect. So the performance is improved by minimizing the interrelation effects. The design process is easy to understand by field engineers working in industries. The simulation results are included in this paper to specify the efficacy of the proposed scheme.
\end{abstract}

Key words - Two variable process, decentralized control, centralized control, interrelation effects, single variable process, servo performance.

\section{INTRODUCTION}

In real time the majority of processes in industries are having more number of inputs and outputs. These processes are popularly known as Multi-Input and Multi-Output (MIMO) processes. Controlling of such processes is very intricate than the processes which are having only single variable.

The multivariable procedures are constrained by two unique approaches. These two methodologies are prevalently known as centralized control and decentralized control plans. The Decentralized (multi-circle) PI/PID control plan utilizes various single variable control schemes. These loops are acquired from multivariable procedures dependent on the interrelations existing between the system variables.

Revised Manuscript Received on November 06, 2019.

M.SWETHA, Currently Working, Master's Degree, JNTUA College Of Engineering, Anantapur, India.

Dr..R.Kiranmayi, Professor \& Head, Department of EEE, JNTUA College Of Engineering, Anantapur.India

N.Swathi, Assistant Professor [Adhoc], Department of EEE, JNTU College Of Engineering, Anantapuramu.
In multiple loop control, the MIMO procedures are served as a combination of multi-single loops, and a controller is structured and actualized on each individual loop by considering loop inter connections. Because of their sensible exhibitions, and structure straightforwardness, multiloop control has been very much acknowledged by the process control industry and extensive exertion has been committed to ameliorate the presentation of multiple loop PI/PID controllers. Diverse control structure systems, for example, detuning factor techniques [1,2], consecutive circle shutting strategies, autonomous control techniques $[3,4]$ and identical exchange work strategies, and so forth [5], have been proposed throughout the years. At the point when the connections between various loops are strong a straightforward multiple loop PI/PID controller is ordinarily sufficient,and the decentralized controller plan strategy is required to give adequate reactions if there exist serious loop communications.

Accordingly, numerous mechanical decentralized controllers are adjusted freely to guarantee system permanence, which causes uneconomical task and higher vitality prices.

For MIMO forms with extreme loop connections, the decoupling control plans are frequently used [6]. The decoupling control more often entails two stages: (1) structure of the decoupler to limit the interrelations between loops; and (2) plan of the principle loop controllers for generally speaking control execution.

The significant points of the decoupling control procedure are that: (1) it permits the utilization of SISO controller plan techniques; and (2) if there is an occurrence of actuator or sensor problems, they are moderately simple to balance out the loop physically, since just one loop is straightly influenced by the failure. In any case, such a plan may result exceptionally confounded control structures, particularly, when the structure measurement is high. Therefore, most of the researches are fundamentally concentrated on two-input and two output (TITO) forms.

For high facet procedures, Wang etal. [7] built up certain strategies for full dimensional PID and non-PID controllers with methodical plan methodology and general straightforward framework structures. In any case, owing to the mathematical estimation of the decouplers for high dimensional procedures, the energy of such a control structure cannot be ensured. Thus, static decoupling strategies which can fundamentally surpass control exhibitions with their 
strong security similar to that of multiple loop control frameworks are applied in the industries to manage serious loop associations for high dimensional MIMO forms.

Despite the fact that static decoupling is easy to plan and actualize, they may not generally give reasonable response of closed loop if there exists enormous contrast in unique attributes among the exchange work components [8].

The arrangement of the paper is accompanied as follows: Section II discussed the representation of two variable systems. Section III presents the control system model using root locus, Section IV presents the case study and proposed algorithm validation, and conclusions are described in sectionV.

\section{REPRESENTATION OF TWO VARIABLE PROCESS}

A schematic depiction of general and proposed closed loop control setup of multivariable procedures are appeared in Fig. 1 and Fig.2 individually. In proposed case, the diagonal controller is utilized for dismissal of loop combinability and set point/reference channel is for following the set point. The components present in proposed control framework are decentralized controller $\mathrm{G}_{\mathrm{c}}(\mathrm{s})$, and process $\mathrm{G}_{\mathrm{p}}(\mathrm{s})$.

For comfort, it is considered that the quantity of controlled factors in multivariable procedures is equivalent to the quantity of controlled factors. This permits blending of single controlled variable with a solitary controlled variable through an analysis of controller.

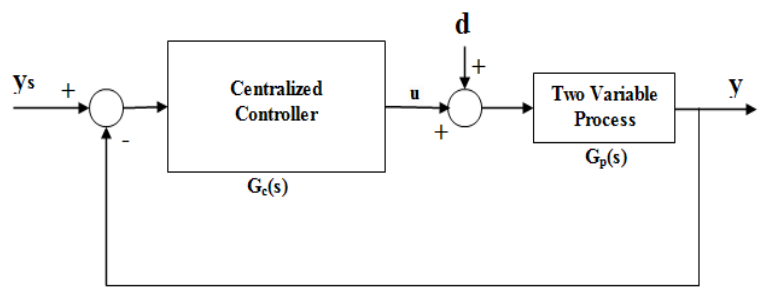

Fig.1.General Structure of closed loop control system

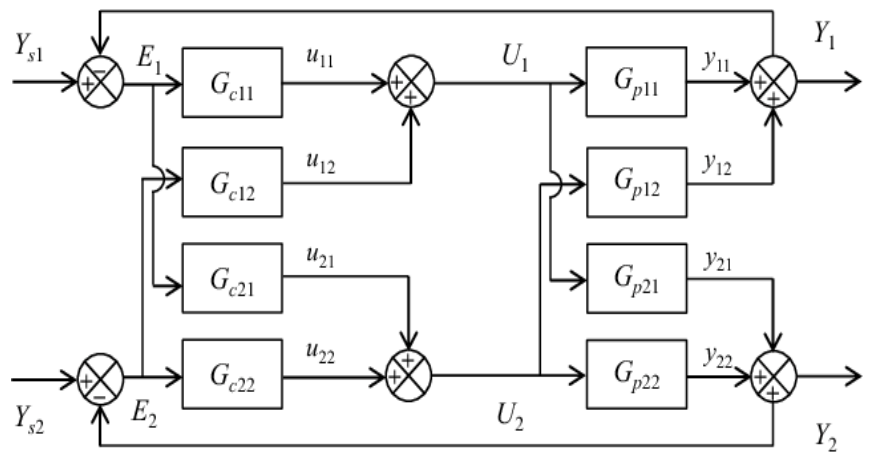

Fig.2.Structure of proposed control system

In general the basic demonstration of the transfer function matrix of the $2 \times 2$ process is:

$$
\mathrm{G}_{\mathrm{p}}(\mathrm{s})=\left[\begin{array}{ll}
\mathrm{G}_{\mathrm{p}_{11}}(\mathrm{~s}) & \mathrm{G}_{\mathrm{p} 12}(\mathrm{~s}) \\
\mathrm{G}_{\mathrm{p}_{21}}(\mathrm{~s}) & \mathrm{G}_{\mathrm{p}_{22}}(\mathrm{~s})
\end{array}\right]
$$

where, the process $\mathrm{G}_{\mathrm{pij}}(\mathrm{s})$ is implicit as first order process with delay time (FOPDT), i.e.,

$$
\mathrm{G}_{\mathrm{pij}}(\mathrm{s})=\frac{\mathrm{K}}{\tau \mathrm{s}+1} \mathrm{e}^{-\theta \mathrm{s}}
$$

The structure of centralized controller is of the form,

$$
\mathrm{G}_{\mathrm{c}}(\mathrm{s})=\left[\begin{array}{ll}
\mathrm{G}_{\mathrm{c}_{11}}(\mathrm{~s}) & \mathrm{G}_{\mathrm{c}_{12}}(\mathrm{~s}) \\
\mathrm{G}_{\mathrm{c}_{21}}(\mathrm{~s}) & \mathrm{G}_{\mathrm{c}_{22}}(\mathrm{~s})
\end{array}\right]
$$

The relation between input and output are noted as [9]:

$$
\begin{gathered}
Y(s)=G_{p}(s) U(s) \\
Y(s)=\left[\begin{array}{l}
y_{1}(s) \\
y_{2}(s)
\end{array}\right], \quad U(s)=\left[\begin{array}{l}
u_{1}(s) \\
u_{2}(s)
\end{array}\right]
\end{gathered}
$$

Where, $\mathrm{Y}(\mathrm{s})$ and $\mathrm{U}(\mathrm{s})$ signifies the output and input vectors of the process respectively. The process input-output correlation for the two variable systems are given as:

$$
\begin{gathered}
Y_{1}(s)=G_{p, 11}(s) u_{1}(s)+G_{p, 12}(s) u_{2}(s) \\
Y_{2}(s)=G_{p, 21}(s) u_{1}(s)+G_{p, 22}(s) u_{2}(s)
\end{gathered}
$$

In the TITO framework, while the subsequent loop is shut, the contribution from $\mathrm{u}_{\mathrm{i}}$ to $\mathrm{y}_{\mathrm{i}}$ has two ways of signal channeling is possible. The mix of two transmission ways is regarded as successful open loop elements. On the off chance that the second criticism controller is in the programmed mode, with $\mathrm{y}_{\mathrm{s} 2}=0$, at that point the generally speaking closed loop model somewhere in the range of $\mathrm{y}_{1}$ and $\mathrm{u}_{1}$ is given by

$$
\frac{y_{1}(s)}{u_{1}(s)}=G_{p 11}(s)-\frac{G_{p 12}(s) G_{p 21}(s) G_{c 2}(s)}{1+G_{c 2}(s) G_{p 22}(s)}
$$

These mathematical relations can be formed as:

$$
\frac{y_{1}(s)}{u_{1}(s)}=G_{p 11}(s)-\frac{G_{p 12}(s) G_{p 21}(s)\left(G_{c 2}(s) G_{p 22}(s)\right)}{G_{p 22}\left(1+G_{c 2}(s) G_{p 22}(s)\right)}
$$

Similarly, for other loops are:

$$
\begin{aligned}
& \frac{y_{1}(s)}{u_{2}(s)}=G_{p 12}(s)-\frac{G_{p 12}(s) G_{p 21}(s)\left(G_{c 2}(s) G_{p 22}(s)\right)}{G_{p 11}\left(1+G_{c 1}(s) G_{p 11}(s)\right)} \\
& \frac{y_{2}(s)}{u_{1}(s)}=G_{p 21}(s)-\frac{G_{p 21}(s) G_{p 12}(s)\left(G_{c 1}(s) G_{p 11}(s)\right)}{G_{p 11}\left(1+G_{c 1}(s) G_{p 11}(s)\right)} \\
& \frac{y_{2}(s)}{u_{2}(s)}=G_{p 22}(s)-\frac{G_{p 21}(s) G_{p 12}(s)\left(G_{c 1}(s) G_{p 11}(s)\right)}{G_{p 11}\left(1+G_{c 1}(s) G_{p 11}(s)\right)}
\end{aligned}
$$

In these two variable frameworks, the open-circle elements between the output control variable $\left(\mathrm{y}_{\mathrm{i}}\right)$ and input controlled variable $\left(\mathrm{u}_{\mathrm{i}}\right)$ not just rely upon the comparing move capacity model $\left(\mathrm{g}_{\mathrm{ii}}\right)$ yet in addition rely upon different procedures and controllers in every single other control loop. This infers the tuning of one controller is impossible autonomously and it relies upon different controllers. The convoluted corelations of eqns. 8 and 9 can be rearranged by accepting two suppositions: First, the ideal controller guess for the other circle (the yield accomplishes unfaltering condition with no transient) was utilized to streamline the eqns. 8 and 9), that is,

$$
G_{11}^{e f f}(s)=\frac{y_{1}(s)}{u_{1}(s)}=G_{p 11}(s)-\frac{G_{p 12}(s) G_{p 21}(s)}{G_{p 22}(s)}
$$

Similarly, the other ETFs are,

$$
\begin{aligned}
& G_{12}^{e f f}(s)=\frac{y_{2}(s)}{u_{1}(s)}=G_{p 12}(s)-\frac{G_{p 11}(s) G_{p 22}(s)}{G_{p 21}(s)} \\
& G_{21}^{e f f}(s)=\frac{y_{2}(s)}{u_{1}(s)}=G_{p 21}(s)-\frac{G_{p 11}(s) G_{p 22}(s)}{G_{p 12}(s)}
\end{aligned}
$$




$$
G_{22}^{e f f}(s)=\frac{y_{2}(s)}{u_{2}(s)}=G_{p 22}(s)-\frac{G_{p 12}(s) G_{p 21}(s)}{G_{p 11}(s)}
$$

Here, $G_{11}$ eff and $G_{22}$ eff are the powerful open-circle move functions (EOTF). These EOTFs are confused transfer function representations, and they are hard to straightforwardly utilize them for the controller structure. Therefore, for maintaining stability of such system can be easily designed with root locus technique. This is explained in sub sequent section.

\section{CONTROL SYSTEM DESIGN USING ROOT LOCUS TECHNIQUE}

In this work, root locus strategy is connected for structuring the control parameters of the modified centralized TITO process. A diagram of control structures comprising of the input controsller $\mathrm{G}_{\mathrm{c}}(\mathrm{s})$ for TITO process is exhibited in Fig,2. Utilizing Root locus strategy for controller plan, the normal for transient reaction and consistent state reaction can be clarified as explained below.

1) The behaviour for transient reaction can be depicted in terms of most extreme percent overshoot $\left(\mathrm{M}_{\mathrm{p}}\right)$.

2) The characteristic attribute for consistent state reaction can be represented in terms of settling time $\left(\mathrm{t}_{\mathrm{s}}\right)$.

The strategy for structuring the enhancing response at the transient state and unfaltering state can be connected by the accompanying steps.

Step 1: choose the damping proportion $(\xi)$, regular recurrence $\left(\omega_{n}\right)$ by considering the behaviour for transient response persistent state response and dominating pole $\left(\mathrm{s}_{\mathrm{d}}\right)$.

$$
\begin{gathered}
M_{p}=100 e^{-\frac{\xi \pi}{\sqrt{1-\xi^{2}}}} \\
t_{s}^{( \pm 2 \%)}=\frac{4}{\xi \omega_{n}} \\
s_{d}=-\xi \omega_{n} \pm j \omega_{n} \sqrt{1-\xi^{2}}
\end{gathered}
$$

Step 2: Determine the summation point at $s_{d}$ of an open loop framework $G_{p}(s) G_{c}(s)$ by graphical strategy or mathematical technique and after that consider the fundamental edge of $\angle\left(s_{d}+z_{c}\right)$ so as to acquire the summation of edge as indicated by the framework condition given in Eqn. (20).

$$
\sum\left(\theta_{z}+\theta_{z c}\right)+\sum \theta_{p}=-(2 k+1) \pi, \quad k=0,1, \ldots . . n
$$

Step 3: Computing the proportional controller gain $\left(\mathrm{K}_{\mathrm{c}}\right)$ using the root locus technique as:

$$
K_{c}=K_{s d}=\frac{1}{\left|G_{p}\left(s_{d}\right) G_{c}\left(s_{d}\right)\right|}
$$

Step 4: To achieve the desired response by applying a unit step signal as input, the forward controller is included in control loop as indicated in Fig. 2 and the form of this is:

$$
G_{f}(s)=\frac{z_{c}}{\left(s+z_{c}\right)}
$$

Step 5: The performance of the proposed centralized control using root locus procdure is evaluated in terms of integral of error over the period of operating time, i.e., integral of absolute error (IAE), integral of the square error (ISE). The Smaller the values of these IAE and ISE indicates the better performance of the system.

These are expressed for TITO process as:

$$
\begin{aligned}
& \text { IAE }=\int_{0}^{\infty}\left(\left|E_{1}(t)\right|+\left|E_{2}(t)\right|\right) d t \\
& \text { ISE }=\int_{0}^{\infty}\left(E_{1}^{2}(t)+E_{2}^{2}(t)\right) d t
\end{aligned}
$$

\section{SIMULATION STUDY}

This examination contemplated the Wood and Berry refining segment process that had presented the exchange capacity design of a pilot-scale refining segment made out of an eight-plate in addition to re-evaporator isolating methanol and water which is run of the mill TITO system with solid association and noteworthy time delays. Subsequently, the Wood-Berry double refining section procedure is considered as the TITO framework that has been widely contemplated by the greater part of the analysts. This procedure can be composed the exchange work framework as given by Eqn. (25).

$$
\mathrm{G}_{\mathrm{p}}(\mathrm{s})=\left[\begin{array}{cc}
\frac{12.8 \mathrm{e}^{-3 \mathrm{~s}}}{16.7 \mathrm{~s}+1} & \frac{-18.9 \mathrm{e}^{-3 \mathrm{~s}}}{21 \mathrm{~s}+1} \\
\frac{6.6 \mathrm{e}^{-7 \mathrm{~s}}}{10.9 \mathrm{~s}+1} & \frac{-19.4 \mathrm{e}^{-3 \mathrm{~s}}}{14.4 \mathrm{~s}+1}
\end{array}\right]
$$

Since it is two variable process, the four PID controllers are required to intend a centralized control for this application and these controllers are designed using root locus approach based on the effective model relations as given below.

$$
\begin{gathered}
G_{11}^{e f f}(s)=\frac{y_{1}(s)}{u_{1}(s)}=\frac{12.8 e^{-3 s}}{16.7 s+1}-\frac{18.9 \times 6.6(14.4 s+1) e^{-7 s}}{19.4(21 s+1)(10.9 s+1)} \\
G_{12}^{e f f}(s)=\frac{y_{1}(s)}{u_{2}(s)}=\frac{-18.9 e^{-3 s}}{21 s+1}-\frac{12.8 \times 19.4(10.9 s+1) e^{-4 s}}{6.6(16.7 s+1)(14.4 s+1)} \\
G_{21}^{e f f}(s)=\frac{y_{2}(s)}{u_{1}(s)}=\frac{6.6 e^{-7 s}}{10.9 s+1}-\frac{12.8 \times 19.4(21 s+1) e^{-10 s}}{18.9(16.7 s+1)(14.4 s+1)} \\
G_{22}^{\text {eff }}(s)=\frac{y_{2}(s)}{u_{2}(s)}=\frac{-19.4 e^{-3 s}}{14.4 s+1}-\frac{18.9 \times 6.6(16.7 s+1) e^{-9 s}}{12.8(21 s+1)(10.9 s+1)}
\end{gathered}
$$

The parameters for full dimensional controller are obtained as:

$\mathrm{G}_{\mathrm{c}, \text { centralized }}(\mathrm{s})=\left[\begin{array}{cc}0.184+\frac{0.0469}{\mathrm{~s}} & -0.0102-\frac{0.0229}{\mathrm{~s}} \\ -0.0674-\frac{4.238}{\mathrm{~s}} & 0.066+\frac{0.0155}{\mathrm{~s}}\end{array}\right]$

For comparison purpose, an inverted decoupler using root locus is also designed for the process as [10]: 


$$
\mathrm{D}(\mathrm{s})_{\text {inverted }}=\left[\begin{array}{cc}
1 & \frac{1.477(16.7 \mathrm{~s}+1) \mathrm{e}^{-2 \mathrm{~s}}}{(21 \mathrm{~s}+1)} \\
\frac{0.34(14.4 \mathrm{~s}+1) \mathrm{e}^{-4 \mathrm{~s}}}{(10.9 \mathrm{~s}+1)} & 1
\end{array}\right]
$$

The TITO procedure was decreased to be single input single output (SISO) framework by utilizing inverted decoupler. The individual loop model of SISO structure comprising of loop 1 $\left(\mathrm{y}_{1}-\mathrm{u}_{1}\right)$ and loop $2\left(\mathrm{y}_{2}-\mathrm{u}_{2}\right)$ are composed as follows.

$$
\begin{aligned}
& \mathrm{T}_{11}(\mathrm{~s})=\frac{1}{1-\frac{0.5017(16.7 \mathrm{~s}+1)(14.4 \mathrm{~s}+1)}{(21 \mathrm{~s}+1)(10.9 \mathrm{~s}+1)}}\left(\frac{12.8}{(16.7 \mathrm{~s}+1)} \mathrm{e}^{-\mathrm{s}}-\frac{6.43(14.4 \mathrm{~s}+1)}{(10.9 \mathrm{~s}+1)(21 \mathrm{~s}+1)} \mathrm{e}^{-7 \mathrm{~s}}\right) \\
& \mathrm{T}_{22}(\mathrm{~s})=\frac{1}{1-\frac{0.5017(16.7 \mathrm{~s}+1)(14.4 \mathrm{~s}+1)}{(21 \mathrm{~s}+1)(10.9 \mathrm{~s}+1)}}\left(\frac{-19.4}{(14.4 \mathrm{~s}+1)} \mathrm{e}^{-3 \mathrm{~s}}-\frac{9.7453(16.7 \mathrm{~s}+1)}{(10.9 \mathrm{~s}+1)(21 \mathrm{~s}+1)} \mathrm{e}^{-9 \mathrm{~s}}\right)
\end{aligned}
$$

In this way, the above can be assessed as the FOPDT model achieved by recurrence response as given by Eqn. (26) and Eqn. (27), individually.

$$
\begin{gathered}
\mathrm{T}_{11}(\mathrm{~s})=\frac{12.7835 \mathrm{e}^{-1.002 \mathrm{~s}}}{(16.671 \mathrm{~s}+1)} \approx \frac{12.7835}{(16.671 \mathrm{~s}+1)(1.002 \mathrm{~s}+1)} \\
\mathrm{T}_{22}(\mathrm{~s})=\frac{-19.3753 \mathrm{e}^{-1.0186 \mathrm{~s}}}{(14.3753 \mathrm{~s}+1)} \approx \frac{-19.3753}{(14.3753 \mathrm{~s}+1)(1.0186 \mathrm{~s}+1)}
\end{gathered}
$$

Root locus strategy was utilized to decide controller parameters of TITO procedure diminished to be SISO structure and the exchange capacities in Eqn. (26) and Eqn. (27) for loop 1 and loop 2, separately, were utilized to structure PID controller. The PID controller for decentralized controller is:

$$
\begin{aligned}
\mathrm{G}_{\mathrm{c} \text {, inverted }}(\mathrm{s}) & =\left[\begin{array}{cc}
\frac{\left(0.4609 \mathrm{~s}^{2}+0.5387 \mathrm{~s}+0.0774\right)}{\mathrm{s}} & 0 \\
0 & \frac{(-0.1213 \mathrm{~s} 2-0.1583 \mathrm{~s}-0.0384)}{\mathrm{s}}
\end{array}\right] \\
\mathrm{G}_{\mathrm{f}}(\mathrm{s}) & =\left[\begin{array}{cc}
\frac{0.1678}{(\mathrm{~s}+0.1678)} & 0 \\
0 & \frac{0.3218}{(\mathrm{~s}+0.3218)}
\end{array}\right]
\end{aligned}
$$

Along these, the PID controller parameters of the Wood-Berry refining process with inverted decoupling by planning of the decentralized PID controller utilizing root locus strategy is determined. For loop 1, the PID controller parameters are, $\mathrm{K}_{\mathrm{p}}=0.5387, \mathrm{~K}_{\mathrm{i}}=0.0774$ and $\mathrm{K}_{\mathrm{d}}=0.4609$. For loop 2, the PID controller parameters are $\mathrm{K}_{\mathrm{p}}=-0.1583$, $\mathrm{K}_{\mathrm{i}}=-0.0384$ and $\mathrm{K}_{\mathrm{d}}=-0.1213$.

For the purpose of simulation, a unit change to the set point contributions for control loop 1 at $\mathrm{t}=0 \mathrm{sec}$ and for control loop 2 at $\mathrm{t}=100 \mathrm{sec}$ is included. The output reactions and control sign of the two control loops are appeared in Figs. 3 and 4 separately. For control loop 1 reaction, it is outlined that the advanced controller plan technique accomplishes a superior performance in terms of quicker settling time (Ts) and littler percent overshoot (Mp) and achieved most extreme control signal. The after effect of output reaction for proposed controller configuration can accomplish the necessity of settling time and percent overshoot. For control loop 2 reactions, the proposed controller configuration gave preferred control execution over control configuration presented by inverted decoupling approach.
The control actions of the two controllers are also depicted in Figs. 5 and 6 respectively. The controller signal of proposed method is smoother than the other approach. This ensures the safety of control element operation in the process industries.

The index of performance of two control loops with the proposed method and inverted decoupler approach designed by root locus strategy is listed in Table I and Table II. This shows the proposed control algorithm is improved the final performance of the system by lessening the interrelation effects of variables.

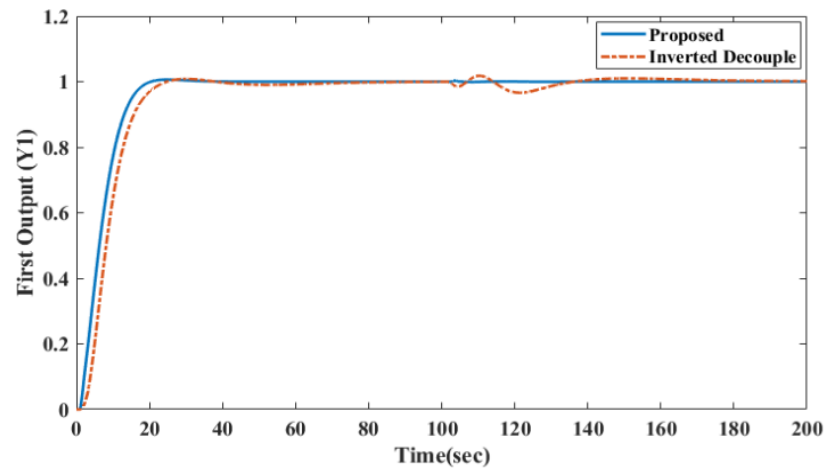

Fig.3. Output Response of the closed loop system (first output $\left(Y_{1}\right)$ ) of WB column

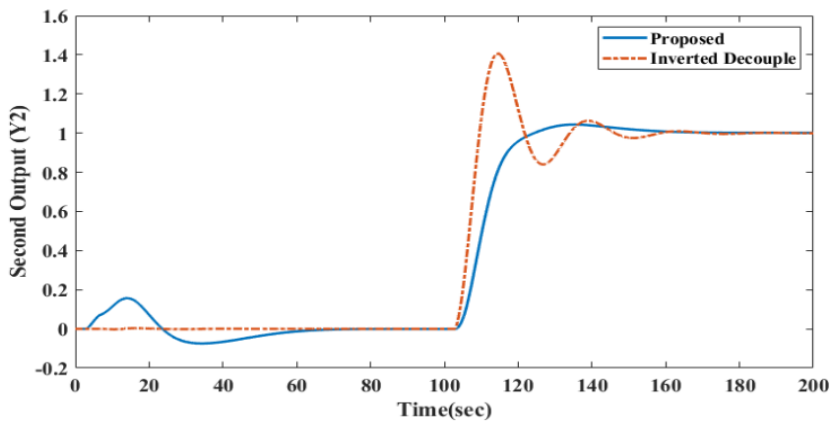

Fig.4.Output Response of the closed loop system (second output $\left(\mathrm{Y}_{2}\right)$ ) of WB column

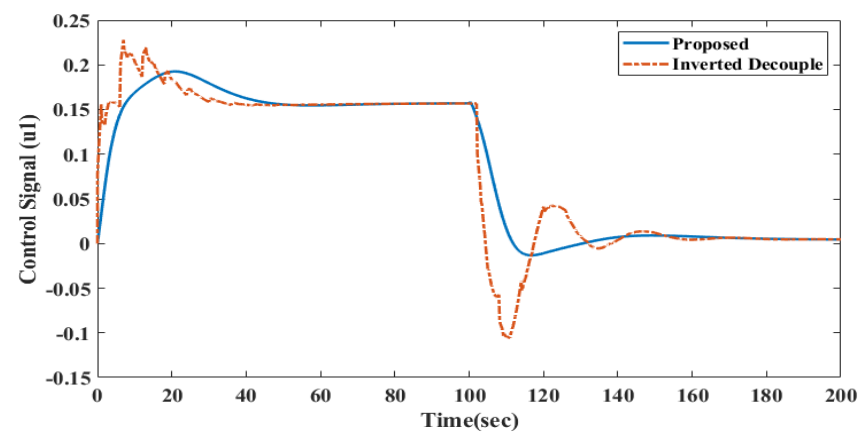

Fig.5. Control signal of first loop $\left(\mathrm{Y}_{\mathrm{s} 1}-\mathrm{U}_{1}\right)$ of $\mathrm{WB}$ column 


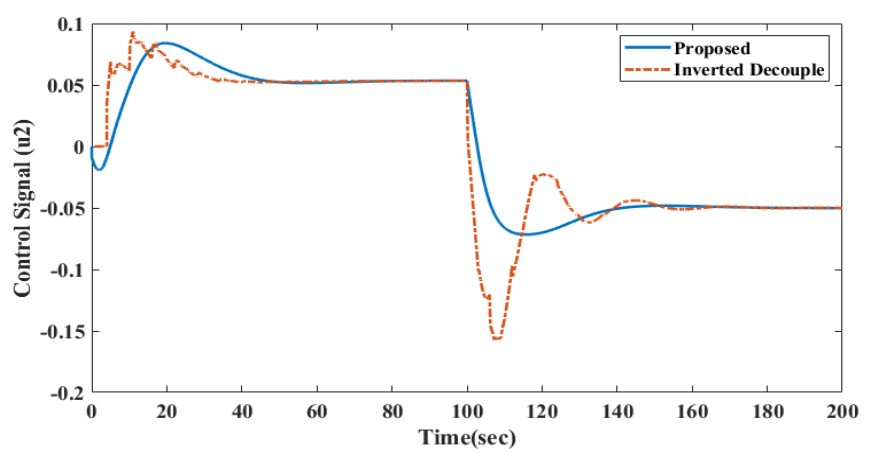

Fig.6. Control signal of second loop $\left(\mathrm{Y}_{\mathrm{s} 2}-\mathrm{U}_{2}\right)$ of WB column

Table I: Performance indices of WB

\begin{tabular}{|c|c|c|c|c|c|c|}
\hline \multirow{2}{*}{ Control Method } & \multicolumn{2}{|c|}{ IAE } & \multicolumn{2}{|c|}{ ISE } & \multirow{2}{*}{ ISE $_{\mathbf{t}}$} \\
\cline { 2 - 3 } & Y1 & Y2 & IAE $_{\mathbf{t}}$ & Y1 & Y2 & ISE $_{\text {Proposed }}$ \\
\hline $\begin{array}{c}\text { Inverted } \\
\text { Decouple }\end{array}$ & 4.984 & 9.013 & 10.997 & 0.0878 & 2.549 & 2.6368 \\
\hline
\end{tabular}

Table II: Time domain Performance of WB

\begin{tabular}{|c|c|c|c|c|c|}
\hline \multirow{2}{*}{$\begin{array}{c}\text { S.N } \\
\text { o }\end{array}$} & \multicolumn{2}{|c|}{ Control Method } & $\begin{array}{c}\text { Rise } \\
\text { time }\left(\mathbf{t}_{\mathbf{r}}\right)\end{array}$ & $\begin{array}{c}\text { Peak } \\
\text { Overshoot } \\
(\mathbf{M p})\end{array}$ & $\begin{array}{c}\text { Settling } \\
\text { Time(t) }\end{array}$ \\
\hline \multirow{2}{*}{1} & \multirow{2}{*}{ Proposed } & $\left(\mathrm{y}_{1}-\mathrm{u}_{1}\right)$ & 10.96 & 0.5 & 15.56 \\
\cline { 3 - 6 } & $\left(\mathrm{y}_{2}-\mathrm{u}_{2}\right)$ & 11.32 & 3.889 & 50 \\
\hline \multirow{2}{*}{2} & \multirow{2}{*}{$\begin{array}{c}\text { Inverted } \\
\text { Decouple }\end{array}$} & $\left(\mathrm{y}_{1}-\mathrm{u}_{1}\right)$ & 11.99 & 0.565 & 32 \\
\cline { 3 - 6 } & $\left(\mathrm{y}_{2}-\mathrm{u}_{2}\right)$ & 4.694 & 40.14 & 65 \\
\hline
\end{tabular}

\section{V..CONCLUSION}

This paper projected the centralized (full dimensional) PID controller structure for two variable procedures utilizing the root locus system. The two variable procedures had incorporated the interactions amid the variables of the system in determining the equivalent model of the process. Each control loop of frame work was approximated as the FOPDT model using ERGA and RFA to use for planning the PID controller. As the PID controller parameters of the related investigation of Wood-Berry refining section procedure were considered, the outcomes demonstrated that the proposed controller can accomplish upright exhibition for supervision the process variables.

\section{REFERENCES}

1. Q. Xiong, W.-J. Cai, M.-J. He, A practical loop pairing criterion for multivariable processes, Journal of Process Control 15 (2005) 741-747.

2. Qiang xiong,Wen-Jian Cai, Mao-Jun He, Equivalent transfer function method for PI/PID controller design of MIMO processes, J.Process control 17(2007) 665-673.

3. Q. Xiong, W.-J. Cai, Effective transfer function method for decentralized control system design of multi-input multi-output processes, Journal of Process Control 16 (2006) 773-784.

4. Naik, R. Hanuma, DV Ashok Kumar, and K. S. R. Anjaneyulu. "Control configuration selection and controller design for multivariable processes using normalized gain." World Acad Sci Eng Technol Int J Electr Comput Electron Commun Eng8.10 (2014).

5. Truong Nguyen Luan Vu and Moonyong Lee,'Independent design of Multiloop PI/PID controllers for Multi-delay processes", world academy science, Engineering and technology,(60)2009,PP 703-708.

6. Tavakoli, Saeed, Ian Griffin, and Peter J. Fleming. "Tuning of decentralised PI (PID) controllers for TITO processes." Control engineering practice 14.9 (2006): 1069-1080.
7. Wang, Qing-Guo, Bin Huang, and Xin Guo. "Auto-tuning of TITO decoupling controllers from step tests." ISA transactions39.4 (2000): 407-418.

8. Naik, R. Hanuma, DV Ashok Kumar, and K. S. R. Anjaneyulu. "A Comparative Study of Decoupler Design Techniques for TITO Control Processes." Emerging Trends in Electrical, Communications and Information Technologies. Springer, Singapore, 2017. 293-301.

9. Seborg, Dale E., et al. Process dynamics and control. John Wiley \& Sons, 2010.

10. Wutthithanyawat, Chananchai, and Santi Wangnipparnto. "Design of decentralized PID controller with the root locus method based on inverted decoupling for a TITO system." Journal of Thai Interdisciplinary Research 13.2 (2018).

\section{AUTHORS PROFILE}

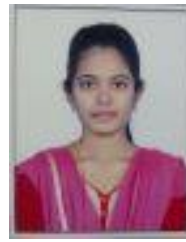

M.Swetha received her Bachelor's Degree from Sri Venkateswara Institute of Science and Technology affiliated to JNTUA, in the year 2017 in Electrical and Electronics Engineering. She is currently working towards her Master's Degree from JNTUA college of engineering, Anantapur, India, in Control System specialization from department of Electrical and Electronics Engineering. In the fulfillment of her Bachelor's Degree she has done Design of Advanced Solar Powered Tricycle. Her research interests are Advanced Control System and Automation Control.

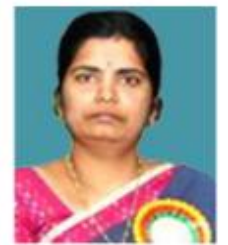

Dr..R.KIRANMAYI M.Tech, Ph.D. Presently working as Professor \& Head of the Department of EEE in JNTUA College of engineering, Anantapur, AP. Her areas of interest include renewable energy sources, electrical power systems. She is a life member of ISTE and IEI.

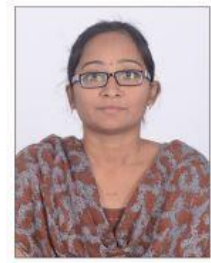

N.SWATHI M.Tech, received B.tech in Electrical and Electronics Engineering in the year 2014 from Sri Venkateswara Institute of Science and technology. She received M.tech in the year 2017 in Control System from JNTU, Anantapur. Currently she is working an Assistant Professor [Adhoc] in the department of EEE at JNTU college of engineering, Anantapuramu. 